\title{
The Palliative Function of Climate Change Denial Is Stronger in More Exposed Countries
}

Hadarics, M. (in press). The palliative function of climate change denial is stronger in more exposed countries. Ecopsychology.

\section{Márton Hadarics}

ELTE Eötvös Loránd University, Budapest, Hungary

\section{Running Head:}

The Palliative Function of Climate Change Denial

keywords:

eco-anxiety; climate change denial; climate change exposure; palliative ideology

\section{Corresponding Author:}

\section{Márton Hadarics}

$\underline{\text { marton.hadarics@ppk.elte.hu }}$

Department of Social Psychology, Eötvös Loránd University

1064, Budapest, Izabella utca 46, Hungary

$+36-30-411-7097$

\section{Author Disclosure Statement}

No competing financial interests exist. 


\begin{abstract}
In our multinational study, we tested whether the palliative effect of climate change denial depends on the local level of climate change exposure. Building upon the literature of ecoanxiety and the palliative function of ideological beliefs, we assumed that the acknowledgement of climate change intensifies eco-anxiety while climate change denial eases it. More importantly, we also assumed that the extent of this ease is larger in countries being more threatened by the harmful consequences of climate change. To test this assumption, we analyzed data collected from representative samples of 23 European countries within European Social Survey Programme, and additional data on the actual exposure of these countries to the effects of climate change. Results of our multilevel models showed that climate change denial is related to lower eco-anxiety, and this negative relationship is stronger at high (vs. low) levels of climate change exposure. Our results support the general principle stating that the harsher reality is, the larger emotional benefit can be achieved by its distorted perception and denial. This psychological defense mechanism can partly explain why many people are reluctant to fight against climate change even in countries that are threatened by it.
\end{abstract}

\title{
keywords:
}

eco-anxiety; climate change denial; climate change exposure; palliative ideology

\section{Introduction}

Climate change has become one of the most pressing issues humanity has to deal with in the forthcoming years. In fact, dealing with this problem can put so much psychological pressure on people that it seriously undermines their mental health and subjective wellbeing (Clayton, Manning, Krygsman \& Speiser, 2017). This phenomenon is mostly described by the concept of eco-anxiety (or climate anxiety), which refers to a high level of anxiety and other 
related difficult emotions arising from the threatening knowledge of negatively changing environmental conditions (Albrecht, 2011; Pihkala, 2018). Seemingly, one of the most basic strategies that can be used to cope with anxiety caused by climate change is simply denying its existence (Norgaard, 2011; Weintrobe, 2013). Nonetheless, we have much less knowledge about under what circumstances climate change denial can ease eco-anxiety. A potential answer to this question may come from the literature of the palliative function of ideological thinking (e.g. Jost \& Hunyady, 2003; Onraet, Van Hiel, \& Dhont, 2013). A part of this literature emphasizes that the harsher social reality is, the more serious damage it can cause in people's subjective well-being. But accordingly, larger psychological benefit can be gained by the justification or denial of that harshness (e.g. Napier \& Jost, 2008; Sengupta, Greaves, Osborne \& Sibley, 2017). This basic principle might be true in the case of climate change too, that is why we assumed and tested that denying the reality of climate change can ease ecoanxiety, and this so called palliative effect can be stronger in countries that are more severely affected by climate change.

\section{Eco-anxiety and denial}

In the last decade, several psychological concepts have been introduced to refer to the negative emotional experiences related to climate change. Eco-anxiety (Albrecht, 2011), environmental anxiety (Pihkala, 2016), solastalgia (Albrecht, 2005), or eco-angst (Goleman, 2009) all describe the negative emotional state arising from the awareness of negative impacts of climate change. Eco-anxiety has a huge potential to undermine mental health and subjective well-being due to its connection with intense negative emotions like depression, anger, fear, a sense of paralysis and hopelessness, or grief (Gillespie, 2016; Pihkala, 2018; Randall, 2009). Furthermore, eco-anxiety promotes destructive behavioral outcomes like alcohol and drug use, workaholism, or imagery distractions (Bodnar, 2008; Gillespie, 2016). 
To overcome eco-anxiety, people apply a wide range of coping mechanisms (Ojala, 2012).

One of the most basic emotion-focused coping strategy is denial, what is a widely used tool to ease existential fear caused by eco-anxiety (Weintrobe, 2013).

But predominantly, climate change denial is not just an individual coping strategy. Since the problem of climate change has become one of the most important issues in global politics, climate change denial has also become a partisan issue and a political ideological element which is deeply embedded into ones political belief-system (Hornsey, Harris, Bain, \& Fielding, 2016; Stanley \& Wilson, 2019).

\section{The palliative function of ideological thinking and denial}

According to the system-justification theory (SJT), to a certain degree, and under certain circumstances, everyone is motivated to think that we live in a fair and just society, where everyone gets what is deserved (Jost \& Banaji, 1994). Because of this motivation, many people tend to rationalize and justify existing social injustices and inequalities, and oppose large-scale societal changes which could undermine the status quo (Jost, 2019). Since climate change, and green movements' policy proposals to overcome it, represent a threat to the existing economic and political status quo, climate change denial is often considered as a motivated system-justifying belief, the purpose of which is to maintain the existing societal arrangements and cultural hierarchies (Feygina, Jost, \& Goldsmith, 2010; Wong-Parodi \& Feygina, 2020).

SJT also point out that endorsing system-justifying ideologies has a palliative function. As a psychological pay-off, mental health and subjective well-being can be maintained and promoted by framing existing social arrangements as just and beneficial (Jost \& Hunyady, 2003). The mechanism of denial arises both directly and indirectly in this process. First, indirect denial appears in the palliative function of the acceptance of ideological beliefs such 
as meritocracy, or sexist and racial stereotypes (e.g. McCoy, Wellman, Cosley, Saslow, \& Epel, 2013; Sengupta et al., 2017; Vargas-Salfate, 2017), since the mere endorsement of these beliefs indirectly questions the existence of any undeserved or unfair form of inequality. Furthermore, some studies tested whether the direct denial of particular social problems is related to psychological well-being. For example, Bahamondes and colleagues (Bahamondes, Sibley, \& Osborne, 2019) found that the subjective well-being of members of low status groups was predicted by group-specific system justification, which relationship was mediated by the denial of discrimination against the respondents' group. Suppes and colleagues (Suppes, Napier, \& Van der Toorn, 2018) also found that several mental health indicators of LGBT respondents were predicted by the denial of discrimination against them.

\section{Contextual moderators of the palliative function}

A line of research within the palliative ideological thinking literature emphasizes the importance of certain contextual factors that can moderate the relationship between ideological beliefs and mental well-being. The general conclusion of these studies is that the harsher reality is, the higher short-term psychological pay-off can be gained by justifying it with appropriate social beliefs. The majority of these studies investigated the moderating role of the degree of actual social inequalities, and found that inequality justifying beliefs (e.g. sexism, racism, or meritocracy belief) predict well-being more strongly in more unequal contexts (Napier \& Jost, 2008; Napier, Thorisdottir, \& Jost, 2010; Sengupta et al., 2017). The same conclusion is suggested by the results of Onraet and colleagues (Onraet, Van Assche, Roets, Haesevoets, \& Van Hiel, 2016) who found that the relationship between right-wing political preferences and psychological well-being was stronger in countries characterized by high levels of threat. 


\section{The current study}

As it is indicated in the palliative ideology literature, macro-level contextual factors can influence the relationship between micro-level (individual) beliefs about social problems and psychological well-being (e.g. Onraet et al., 2016; Sengupta et al., 2017). In our study, we attempted to test whether this moderating effect can be observed in the realm of climate change beliefs. More specifically, we tested whether climate change denial has a potential to ease eco-anxiety, and more importantly, we also tested whether this potential, if it exists, is stronger in countries that are more intensely threatened by the harmful direct and indirect effects of climate change.

To test these assumptions about individual-level climate change beliefs and macrolevel climate change exposure, we relied on a large-scale international survey database: the European Social Survey (ESS). The ESS is an academically driven international survey program that has been administered regularly with the participation of more than 30 European countries in total. This survey measures the attitudes, beliefs, and behavior patterns of diverse populations across a wide range of European countries, which makes it an ideal tool for international comparative studies. We analyzed the dataset from the 8th data collection round (European Social Survey Round 8 Data, 2016). This database contains data collected from probabilistic representative samples of 23 countries $(\mathrm{N}=44,387)^{1}$. Furthermore, this particular data collection round contained a questionnaire module specifically designed to assess respondents' environmental and climate change beliefs.

\section{Measures}

\footnotetext{
${ }^{1}$ Participating countries: Austria, Belgium, Czech Republic, Estonia, Finland, France, Germany, Hungary, Iceland, Ireland, Israel, Italy, Lithuania, Netherlands, Norway, Poland, Portugal, Russian Federation, Slovenia, Spain, Sweden, Switzerland, United Kingdom. For more information on the sampling and data collection procedure of the European Social Survey: https://www.europeansocialsurvey.org/methodology/ess methodology/sampling.html https://www.europeansocialsurvey.org/methodology/ess methodology/data collection.html
} 
Eco-anxiety. Anxiety related to climate change was measured with the following question in the ESS questionnaire: "How worried are you about climate change?" $(1=$ not at all worried; 5 = extremely worried).

Climate change denial. Climate change denial was measured with the following question: "You may have heard the idea that the world's climate is changing due to increases in temperature over the past 100 years. What is your personal opinion on this? Do you think the world's climate is changing?" ( 1 = definitely changing; 4 = definitely not changing). Climate change exposure. To measure country-level climate change exposure, we relied on the "Exposure" subscore of the Notre Dame Global Adaptation Initiative (NA-GAIN) index (Chen et al., 2015). The ND-GAIN index summarizes a country's vulnerability to climate change in combination with its readiness to improve resilience. Its "Exposure" subscore indicates "the extent to which human society and its supporting sectors are stressed by the future changing climate conditions. Exposure in ND-GAIN captures the physical factors external to the system that contribute to vulnerability." (Chen et al., 2015, p. 3.). Based on a wide range of indicators, country scores measure how seriously six socially relevant areas (health, ecosystems, infrastructure, habitat, food, and water) within a country are to be impaired by the long-term effects of climate change. We applied the 2017 scores from the ND-GAIN database (Notre Dame Global Adaptation Initiative, 2020).

Control variables. We included control variables in the analyses both on individual and national levels. These included respondents' gender $(0=$ man; $1=$ woman $)$, age, education (number of years spent with full-time education), household income, and left-right ideological identification $(0=$ left; $10=$ right $)$. This latter variable was important to be included because of the well documented relationship between climate change beliefs and ideological preferences (e.g. Hornsey et al., 2016; Stanley \& Wilson, 2019). On the national level, we controlled for the quality of life in each country indicated by the 2016 Human Development 
Index (HDI), which is a global measure developed within the United Nations Development Programme (2019) composed by measures of income, age expectancy, and educational level.

Analytic strategy

We applied a multilevel linear modeling strategy to test our hypothesis, which choice was made due to the nested nature of our dataset, where respondents are grouped according to their nationality. Multilevel modeling is also an appropriate tool to test cross-level interactions, which was one of our goals related to our hypotheses about the contextual influence of climate change exposure. Before the modeling procedure, individual-level predictors were group-mean centered, and country-level predictors were grand-mean centered. The data was weighted with the post-stratified design weight that adjusts for both the unequal probability of sampling selection and any differences that may still occur due to differential nonresponse or random sampling variability. ${ }^{2}$

When doing the analysis, we set up three models with restricted maximum likelihood estimation with eco-anxiety as dependent variable: an empty linear model with a fixed intercept, another empty model with random intercepts in order to justify our multilevel modeling approach, and a third random intercept model with the country- and individual-level predictor variables. This latter model also included an interaction term between country-level climate change exposure and individual-level climate change denial. All statistical analyses were conducted with the SPSS 25.0 software (IBM Corp., 2017).

Results

\footnotetext{
${ }^{2}$ For more information on the weighting procedures in ESS datasets see: https://www.europeansocialsurvey.org/docs/methodology/ESS_weighting_data_1.pdf https://www.europeansocialsurvey.org/docs/round8/methods/ESS8 weighting strategy.pdf
} 
Descriptive statistics and pooled correlations between the variables are presented in

Table 1. Results of our analyses showed that the random intercept model showed a significantly better fit than the fixed intercept model, which result supports the multilevel modeling process (fixed intercept model: $-2 \log =115,439.76 ; A I C=115,441.76$; random intercept model: $\left.-2 \log =112,752.76 ; A I C=112,756.76 ; \chi^{2}=2,687 ; d f=1 ; p<.001\right)$. Adding the predictors also enhanced the model fit compared to the empty model $\left(\chi^{2}=37,488.44 ; d f=\right.$ $9 ; p<.001)$.

Table 1. Descriptive statistics and correlations between variables based on the pooled ESS dataset.

\begin{tabular}{|c|c|c|c|c|c|c|c|c|c|}
\hline & 1. & 2. & 3. & 4. & 5. & 6. & 7. & 8. & 9. \\
\hline 1. Eco-anxiety & 1.00 & $-.35 * * *$ & $.09 * * *$ & $.05 * * *$ & $.06 * * *$ & $-.03 * * *$ & $.09 * * *$ & $.05 * * *$ & $-.13 * * *$ \\
\hline 2. Climate change denial & & 1.00 & $-.04 * * *$ & $-.13 * * *$ & $-.03 * * *$ & $.04 * * *$ & $-.10 * * *$ & $-.04 * * *$ & $.10^{* * *}$ \\
\hline 3. Climate change exposure & & & 1.00 & $.06 * * *$ & .00 & $.03 * * *$ & $.04 * * *$ & $.05 * * *$ & $-.07 * * *$ \\
\hline 4. Human Development Index & & & & 1.00 & $-.03 * * *$ & .00 & $.17 * * *$ & $.04 * * *$ & $-.04 * * *$ \\
\hline 5. Gender & & & & & 1.00 & $.05 * * *$ & .00 & $-.08 * * *$ & $-.05 * * *$ \\
\hline 6. Age & & & & & & 1.00 & $-.21 * * *$ & $-.20 * * *$ & $.02 * * *$ \\
\hline 7. Education & & & & & & & 1.00 & $.34 * * *$ & $-.04 * * *$ \\
\hline 8. Income & & & & & & & & 1.00 & $.04 * * *$ \\
\hline 9. Left-right ideology & & & & & & & & & 1.00 \\
\hline $\operatorname{Mean}(N)$ & 3.01 & 1.52 & 0.38 & 0.90 & 44,387 & 47.04 & 12.86 & 5.36 & 5.17 \\
\hline$S D$ & .94 & .69 & 0.05 & 0.04 & $\begin{array}{l}(22,944 \\
\text { female })\end{array}$ & 18.73 & 3.83 & 2.73 & 2.23 \\
\hline
\end{tabular}

Note. ${ }^{*} p<.05 . * * p<.01 . * * * p<.001$

Details of the model with the predictors are presented in Table 2. Here, the unstandardized regression coefficients $(b)$ for each predictor can be found along with their standard errors $(S E), 95 \%$ confidence intervals (CI 95\%), and significance levels $(p)$. These results show that from the country-level predictors, neither the HDI nor climate change exposure had a significant main effect on eco-anxiety. Nonetheless, except for household income, all individual-level variables significantly predicted eco-anxiety. These results indicate that women, younger and more highly educated people are more likely to experience eco-anxiety, just like those with a leftist ideological preference. Climate change denial was 
also a significant predictor, but more importantly, its interaction with climate change exposure was significant too.

Table 2. Multilevel linear model predicting eco-anxiety.

\begin{tabular}{cccc}
\hline & $b(S E)$ & $C I 95 \%$ & $p$ \\
\cline { 2 - 4 } Intercept & $2.98(.05)$ & $2.87,3.09$ & $<.001$ \\
Climate change denial & $-0.51(0.01)$ & $-0.52,-0.49$ & $<.001$ \\
Climate change exposure & $1.12(1.07)$ & $-1.12,3.33$ & .312 \\
Human Development Index & $0.92(1.45)$ & $-2.11,3.95$ & .534 \\
Gender & $0.10(0.01)$ & $0.08,0.12$ & $<.001$ \\
Age & $-1 \mathrm{E}-3(2.74 \mathrm{E}-4)$ & $-1 \mathrm{E}-3,-4.2 \mathrm{E}-4$ & $<.001$ \\
Education & $0.01(1 \mathrm{E}-3)$ & $0.01,0.02$ & $<.001$ \\
Income & $2 \mathrm{E}-3(2 \mathrm{E}-3)$ & $-2 \mathrm{E}-3,6 \mathrm{E}-3$ & .263 \\
Left-right ideology & $-0.03(0.002)$ & $-0.03,-0.02$ & $<.001$ \\
change denial & $-0.39(0.16)$ & $-0.71,-0.07$ & .018 \\
$-2 \log$ & & $75,268.32$ & \\
AIC & & $75,272.32$ & \\
\hline
\end{tabular}

To probe this latter interaction further, we ran a simple slope analysis, which showed that the negative relationship between climate change denial and eco-anxiety was stronger at a high level ( $+2 \mathrm{SD}$ from the mean) of climate change exposure $(b=-.55 ; S E=.02 ; \mathrm{CI} 95 \%[-$ $.59,-.51] ; p<.001)$ than at a low level $(-2$ SD from the mean) of it $(b=-.46 ; S E=.019 ; \mathrm{CI}$ $95 \%[-.50,-.43] ; p<.001)$. This indicates that the statistical effect of climate change denial on eco-anxiety gradually intensifies with the crescendo of contextual climate change exposure (see Figure 1). 


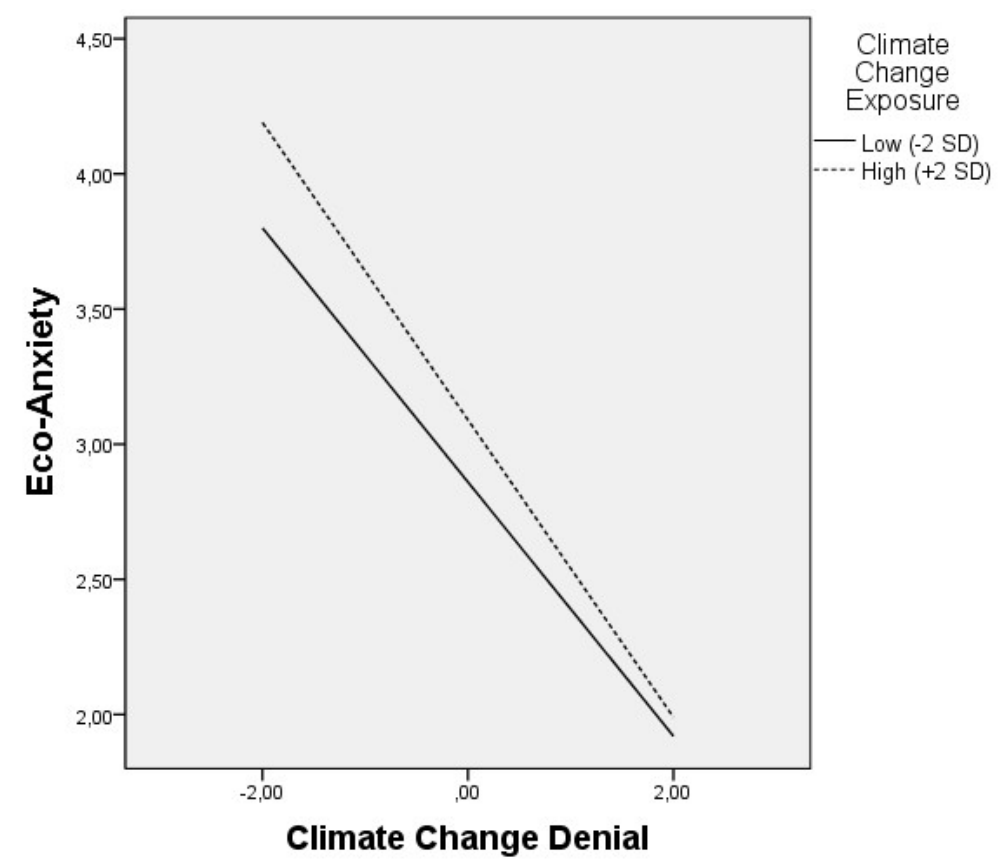

Figure 1. The effect of climate change denial on eco-anxiety in countries with high and low levels of climate change exposure

\section{Discussion}

In our study, we tested how country-level climate change exposure moderates the relationship between climate change denial and eco-anxiety. According to our knowledge, this was the first study investigating the influence of a climate change-related macro-level factor on the palliative effect of climate change beliefs, and more generally, the first study testing the moderating effect of a contextual factor on the palliative effect of a denying social belief. We already knew from previous studies that denying social and ideological beliefs have a palliative effect (Bahamondes et al., 2019; Suppes et al., 2018), and climate change denial, as a specific denying belief, is related to a lower level of anxiety (Pihkala, 2018; Weintrobe, 2013). Taking a step further, we hypothesized and found that the palliative function of climate change denial is stronger in countries that are more severely threatened by the long-term effects of climate change. 
Nonetheless, this does not mean that citizens of countries which are more endangered by climate change are more motivated to deny the mere existence of climate change, but our results implicate that the short-term emotional pay-off of denial is more substantial in these countries. This brings up the possibility that any persuasion attempts or therapeutic techniques targeting to build down climate change denial in these countries might result in a more intense initial resistance and defense of these denying beliefs due to the stronger palliative effect of denial. Future research should test whether deniers themselves are more motivated in these countries to maintain denial because giving it up would raise more eco-anxiety than in countries where reality is less threatening.

Nevertheless, it is important to note that the moderating effect of climate change exposure can depend on the specific nature of threat it means to people individually. In our study, we used the Exposure subscore of the ND-GAIN index to operationalize climate change exposure. As it was mentioned above, this measure captures through multiple indicators how climate change affects the long-term functioning of whole societies. These effects threaten everyone, the society as a whole, but they evolve slowly and gradually. On the other hand, other consequences of climate change, typically natural disasters, affect less people directly, but their magnitude and significance are more difficult to deny for those directly involved. In the case of these kinds of threats, climate change denial might have less palliative potential than other possible ideological beliefs. For example, if the fact of change is difficult to deny, people can still frame it as a natural process, and not human-induced. Future research can reveal whether specific climate change beliefs have varying palliative power depending on the specific climate change-related threat they are to eliminate.

It is also important to emphasize that the palliative function of climate change denial most probably works only in the short run. Longitudinal studies investigating other systemjustifying ideologies show that their relationship with different indicators of subjective well- 
being is positive only temporarily, but turn to be negative after a while among those being in a disadvantageous position within the system (Godfrey, Santos, \& Burson, 2019; Harding \& Sibley, 2013). This suggests that a distorted perception or rationalization of reality have a backlash effect on the mental health of those who are endangered by that reality. We can assume that the wider the gap between reality and perception is, the stronger this backlash can be in terms of psychological well-being. Future research should also investigate this possibility, and test whether maintaining climate change denial undermines deniers' mental health to a larger extent in the long run in more severely affected countries than in countries being less exposed to the effects of climate change.

Furthermore, it is also important to point out that denial is normally a temporary phase in a loss-related coping process, what is ideally followed by the gradual acceptance of reality, and a constructive adaptation to it (Weintrobe, 2013). Nonetheless, societal adaptation to climate change requires tremendous financial resources, what are most needed in the very countries which are globally the most exposed to the harmful consequences of climate change (Notre Dame Global Adaptation Initiative, 2020). Consequently, the situation of these countries is morefold problematic, as they have to struggle with the direct physical effects of climate change with limited resources, and with all the mental health issues that are related to these effects once people acknowledge them. Simultaneously, better-off Western countries are not just less exposed to climate change and possess more resources to the fight against it, but as our results suggest, the acknowledgement of climate change causes less anxiety in these less exposed countries.

Availability of financial resources might count also on an individual level. Climate change denial can be more easily maintained by those who possess sufficient resources to eliminate consequences of climate change from their lives, because they do not have to face these consequences on a daily basis. Members of dominant and privileged social groups, who own 
these resources, can be motivated to maintain their denial for multiple reasons. That is because they can avoid eco-anxiety, but they can also justify their advantageous social position by claiming that the currently operating economic and political mechanisms, which keep them dominant, do not harm the global climate (Feygina, Jost, \& Goldsmith, 2010; Wong-Parodi \& Feygina, 2020). Finally, since their intense consumer behavior is an important factor in climate change, by denying it, they can also prevent eco-guilt, an uncomfortable feeling arising from not meeting certain standards for environmental behavior (Mallett, 2012).

Finally, we have to point out some shortcomings of our study. Although, by applying ESS data we had access to data collected from representative samples of 23 countries, all these countries are located within a limited geographical region of our planet, namely Europe. Consequently, the variability of their exposure to climate change is also inevitably modest on a global scale, that is why we can assume that the moderating role of climate change exposure would be even stronger if we had the opportunity to analyze data on climate change denial and eco-anxiety beyond Europe, from multiple geographical regions. Additionally, we were constrained by the operationalizations in the ESS survey, and consequently, the analyzed variables were measured by single items instead of validated multiple-item scales.

Furthermore, it has to be noted that our study was a correlational one, and as such, it is not suitable to make conclusions about causal effects. Although it is heavily emphasized in the eco-anxiety literature that denial is one of the most basic tools for easing eco-anxiety (Pihkala, 2016; Weintrobe, 2013), it is also possible that those who are not anxious about climate change collect less information on it in the first place, or just simply ignore these, and consequently, they become less aware of the harsh reality of climate change. Future longitudinal research could be helpful in untangling the temporal relationship-pattern between climate change denial and eco-anxiety. 


\section{Conclusion}

Our results indicate that climate change denial eases eco-anxiety to a larger extent in countries which are more exposed to the harmful effects of climate change. This is in accordance with the general principle stating that the harsher reality is, the larger palliative benefit can be achieved by denying it. In this case this means that the struggle against climate change is cumulatively difficult in the most severely affected countries. Beyond the fight against the direct effects, easing mental effects can be problematic too, because breaking potential denial in these countries would be a necessary requirement to initiate social change and collective action, but the acknowledgement of climate change increases anxiety to a higher extent than in more fortunate countries. But accepting reality is unavoidable for changing it, and it is a global responsibility to provide help for those who need it.

\section{References}

Albrecht, G. (2005). 'Solastalgia'. A new concept in health and identity. PAN: Philosophy Activism Nature, 41-55.

Albrecht, G. (2011). Chronic environmental change: Emerging "psychoterratic" syndromes. In I. Weissbecker (Ed.), Climate change and human well-being. International and cultural psychology (pp. 43-56). Washington, DC: Springer.

Bahamondes-Correa, J., Sibley, C. G., \& Osborne, D. (2019). "We look (and feel) better throughsystem-justifying lenses": System-justifying beliefs attenuate the well-being gap between the advantaged and disadvantaged by reducing perceptions of discrimination. 
Personality and Social Psychology Bulletin. Advance online publication.

https://doi.org/10.1177/0146167219829178

Bodnar, S. (2008). Wasted and bombed: Clinical enactments of a changing relationship to the earth. Psychoanalytic Dialogues, 18, 484-512.

Chen, C., Noble, I., Hellmann, J., Coffee, J., Murillo, M., \& Chawla, N. (2016). University of Notre Dame Global Adaptation Index Country Index Technical Report. Available at: https://gain.nd.edu/assets/254377/nd_gain technical_document_2015.pdf

Clayton, S., Manning, C., Krygsman, K., \& Speiser, M. (2017). Mental health and our changing climate: impacts, implications, and guidance. Washington, DC: American Psychological Association and ecoAmerica.

European Social Survey Round 8 Data (2016). Data file edition 2.1. NSD - Norwegian Centre for Research Data, Norway - Data Archive and distributor of ESS data for ESS ERIC. doi:10.21338/NSD-ESS8-2016.

Feygina, I., Jost, J. T., \& Goldsmith, R. E. (2010). System justification, the denial of global warming, and the possibility of "system-sanctioned change". Personality and Social Psychology Bulletin, 36, 326-338.

Gillespie, S. (2016). Climate change imaginings and depth psychology: Reconciling present and future worlds. In J. P. Marshall \& L. H. Connor (Eds.), Environmental change and the world's futures: Ecologies, ontologies and mythologies (pp. 181-195.) New York: Routledge. 
Godfrey, E. B., Santos, C. E., \& Burson, E. (2019). For better or worse? System-justifying beliefs in sixth-grade predict trajectories of self-esteem and behavior across early adolescence. Child Development, 90, 180-195.

Goleman, D. (2009). The age of eco-angst. The New York Times, Sept. 27. https://opinionator.blogs.nytimes.com/2009/09/27/the-age-of-eco-angst/

Harding, J. F., \& Sibley, C. G. (2013). The palliative function of system justification: Concurrent benefits versus longer-term costs to wellbeing. Social Indicators Research, 113, 401-418.

Hornsey, M. J., Harris, E. A., Bain, P. G., \& Fielding, K. S. (2016). Meta-analyses of the determinants and outcomes of belief in climate change. Nature Climate Change, 6, 622-626.

IBM Corp. (2017). IBM SPSS Statistics for Windows, Version 25.0. Armonk, NY: IBM Corp.

Jost, J. T. (2019). A quarter century of system justification theory: Questions, answers, criticisms, and societal applications. British Journal of Social Psychology, 58, 263-314.

Jost, J. T., \& Banaji, M. R. (1994). The role of stereotyping in system-justification and the production of false consciousness. British Journal of Social Psychology, 33, 1-27.

Jost, J. T., \& Hunyady, O. (2003). The psychology of system justification and the palliative function of ideology. European Review of Social Psychology, 13, 111-153. 
Mallett, R. K. (2012). Eco-guilt motivates eco-friendly behavior. Ecopsychology, 4, 223-231.

McCoy, S. K., Wellman, J. D., Cosley, B., Saslow, L., \& Epel, E. (2013). Is the belief in meritocracy palliative for members of low status groups? Evidence for a benefit for selfesteem and physical health via perceived control. European Journal of Social Psychology, 43, $307-318$

Napier, J. L., \& Jost, J. T. (2008). Why are conservatives happier than liberals? Psychological Science, $19,565-572$.

Napier, J. L., Thorisdottir, H., \& Jost, J. T. (2010). The joy of sexism? A multinational investigation of hostile and benevolent justifications for gender inequality and their relations to subjective well-being. Sex Roles, 62, 405-419.

Norgaard, K. M. (2011). Living in denial: Climate change, emotions, and everyday life. Cambridge: MIT Press.

Notre Dame Global Adaptation Initiative (2020). ND-GAIN Vulnerability Exposure Country Ranking Scores. Available at: https://gain.nd.edu/our-work/country-index/rankings/

Ojala, M. (2012). Hope and climate change: The importance of hope for environmental engagement among young people. Environmental Education Research, 18, 625-642. 
Onraet, E., Van Assche, J., Roets, A., Haesevoets, T., \& Van Hiel, A. (2017). The happiness gap between conservatives and liberals depends on country-level threat: A worldwide multilevel study. Social Psychological and Personality Science, 8, 11-19.

Onraet, E., Van Hiel, A., \& Dhont, K. (2013). The relationship between right-wing ideological attitudes and psychological well-being. Personality and Social Psychology Bulletin, 39, 509-522.

Pihkala, P. (2016). The pastoral challenge of the Environmental Crisis: Environmental anxiety and Lutheran eco-reformation. Dialog, 55, 131-140.

Pihkala, P. (2018). Eco-anxiety, tragedy, and hope: Psychological and spiritual dimensions of climate change. Zygon, 53, 545-569.

Randall, R. (2009). Loss and climate change: The cost of parallel narratives. Ecopsychology, $1,118-129$.

Sengupta, N. K., Greaves, L. M., Osborne, D., \& Sibley, C. G. (2017). The sigh of the oppressed: The palliative effects of ideology are stronger for people living in highly unequal neighbourhoods. British Journal of Social Psychology, 56, 437-454.

Stanley, S. K., \& Wilson, M. S. (2019). Meta-analysing the association between social dominance orientation, authoritarianism, and attitudes on the environment and climate change. Journal of Environmental Psychology, 61, 46-56. 
Suppes, A., Napier, J. L., \& van der Toorn, J. (2019). The palliative effects of system justification on the health and happiness of lesbian, gay, bisexual, and transgender individuals. Personality and Social Psychology Bulletin, 45, 372-388.

United Nations Development Programme (2019). Human Development Data (1990-2018). Retrieved from: http://www.hdr.undp.org/en/data

Vargas-Salfate, S. (2017). The palliative function of hostile sexism among high and lowstatus Chilean students. Frontiers in Psychology, 8, 1733.

Weintrobe, S. (2013). The difficult problem of anxiety in thinking about climate change. In S. Weintrobe (Ed.), Engaging with climate change. Psychoanalytic and interdisciplinary perspectives (pp. 33-47). New York: Routledge.

Wong-Parodi, G., \& Feygina, I. (2020). Understanding and countering the motivated roots of climate change denial. Current Opinion in Environmental Sustainability. Advance online publication. https://doi.org/10.1016/j.cosust.2019.11.008 